\title{
The Effects of Cervical and Lumbar Stabilization Exercises on Quantitative Sensory Testing and Muscular Activity in Patients with Neck Pain
}

\author{
Il-Yong Jang ${ }^{1}$, Byong-Yong Hwang ${ }^{*}$ \\ 'Dept. of Physical Therapy, Gwangju-Health University, \\ ${ }^{* 2}$ Dept. of Physical Therapy, College of Health Welfare, Yong-In University
}

Purpose The purpose of this study was to investigate the effects of cervical and lumbar stabilization exercises on quantitative sensory testing (QST) and muscular activity in patients with neck pain. Methods A total of 40 patients were randomly allocated into one of the two groups: The cervical stabilization exercise group ( $n=20)$, and the lumbar stabilization exercise group $(n=20)$. All the patients in the two groups were trained for 40 minutes a day, 3 times a week for 8 weeks in different places. QST were assessed using cold sensation threshold (CST), warm sensation threshold (WST), cold pain threshold (CPT), heat pain threshold (HPT), in addition muscular activity were assessed using sternocleidomastoid (SCM) muscle, and anterior scalene muscle. Results These result lead us to the conclusion that each group were statistically improved at QST and muscle activity, but cervical stabilization exercise group compared with lumbar stabilization exercise group was more significant improvement. Conclusion Cervical and lumbar stabilization exercises has positive effects that are Enhancing QST and muscular activity management in patients with neck pain.

Key words Neck pain, Cervical and lumbar stabilization exercises, Quantitative sensory testing, Muscular activity, Sternocleidomastoid muscle, Anterior scalene muscle

Corresponding author Byong-Yong Hwang (bhwang@yongin.ac.kr)

Received date 7 February 2018

Revised date 12 February 2018

Accepted date 21 February 2018

\section{Introduction}

Information technology (IT) devices are increasingly used in modern times and this has been shown to correlate with an escalation in neck pain in general. ${ }^{1)}$ Cervical and shoulder pain affects students and office workers, in particular, as they spend lengthy periods sitting in a chair. ${ }^{2)}$ The number of patients with neck pain was shown to accelerate constituting a considerable portion of the social and economic burden. ${ }^{3)}$ Neck pain, also referred to as neck and shoulder joint syndrome, involves pain and limited joint mobility in the neck and shoulder tissues. ${ }^{4}$ Stress on the cervical spine, owing to the type of occupation or lifestyle, is the primary cause of neck pain. ${ }^{5)}$ Stress leads to the excessive use of and abnormal movement in the cervical

doi : http:dx.doi.org/10.17817/2018.02.09.111242 spine, thus causing chronic neck pain. ${ }^{6}$ Neck pain contributes significantly to the health burden on society as it leads to physical disorders, a reduction in work performance, and decreased quality of life. ${ }^{7)}$ The amount of time spent engaged in physical exercise and activity is also decreasing in correlation with the amount of time spent using IT devices. ${ }^{8)}$ when the posture used is incorrect. As a result, fatigue accumulates in the neck, increasing the risk of neck pain. ${ }^{9)}$

The recovery of mobility and stability, and a reduction in pain, should be the primary goals of treating patients with neck pain. Ensuring improvement in muscular strength, endurance, and range of motion of the cervical spine can be achieved through exercise. ${ }^{10}$ Adequate tension in the muscles surrounding the cervical spine is essential to ensure stability and mobility therein. ${ }^{11)}$ It has been reported that the superficial muscles (i.e., the scalene and sternocleidomastoid 
muscles) are appreciably more involved in ensuring stability and mobility of the cervical spine than the deep muscles. ${ }^{12)}$ Incorrect posture causes asymmetry of the trunk and changes in the musculoskeletal structure, which further negatively impacts on the ability to maintain the correct posture. ${ }^{13)}$ The habitual use of incorrect posture was demonstrated to result in differences in leg length in college students, ${ }^{14)}$ while habit of leg crossing was shown to cause non-alignment of the pelvis. ${ }^{15)}$ Thus, the daily practice of ensuring correct postural control, to maintain correct alignment of the spine and pelvis, is important. Trunk stabilization, achieved by ensuring continuous tension in the muscles surrounding the spine and pelvis, is the most optimal way of achieving cervical spine stability. ${ }^{16}$

Varied intervention methods aimed at improving stability and mobility of the cervical and lumbar spine have been evaluated in several studies. ${ }^{15,17)}$ Of these, cervical and lumbar stabilization exercises were reported to be the most effective as they were able to control an unstable posture in a balanced way, and improve stability and mobility by stimulating co-contraction of the muscles surrounding the cervical spine, spine, and pelvis without causing pain. ${ }^{18)}$ For this reason, and owing to their ability to minimize mechanical stress, ${ }^{19)}$ they have been applied to various populations, including office workers, ${ }^{20)}$ patients with chronic back pain, ${ }^{21)}$ stroke patients, ${ }^{22)}$ and those with neck pain. ${ }^{23)}$

However, the focus of existing research, which has been fragmented, has been on changes in muscular activity and alignment of the cervical spine using cervical stabilization exercises primarily, or on changes in muscular activity and alignment of the lumbar spine and pelvic region using lumbar stabilization exercises. At present, there is a scarcity of studies in which muscular activity and pain in the cervical spine have been evaluated using a cervical stabilization exercises and lumbar stabilization exercises. Thus, the effect of the application of cervical and lumbar stabilization exercises on muscular activity and cervical pain in patients with chronic neck pain was evaluated in the current study.

\section{Materials and Methods}

\section{Subjects}

Forty patients presenting due to neck pain at the Department of Neurosurgery and Orthopedics, at Hospital S, located in G Metropolitan City, South Korea, and who agreed to participate in the study were included. Patients with structural deficits, such as fractures, inflammation, or severe degenerative disease, or those who had to undergo surgery, were excluded. The general characteristics of the research subjects is provided in Table 1.

\section{Intervention}

The participants were randomly allocated to either a cervical stabilization exercise or a lumbar stabilization excerise group. Each group performed 40-minute exercises three times a week, for a total of eight weeks. Tables $2^{24)}$ and Table $3^{25)}$ describe the exercise program applied to the cervical stabilization exercise group and lumbar stabilization exercise group, respectively.

\section{Measurement of muscular activity}

Muscular activity pertaining to the sternocleidomastoid and anterior scalene muscles was measured using surface electromyography (Mega Electronics Biomonitor

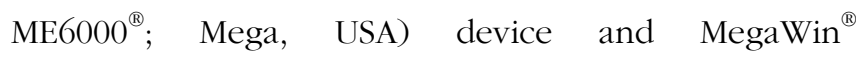
(version2.3) software. To normalize it, it was first measured underconditions of voluntary isometric contraction. The percentage of maximal voluntary contractions (\%MVC) of each muscular activity was determined and computed as the root mean square. ${ }^{26)}$

Table 1. General Characteristics of the subjects

\begin{tabular}{cccc}
\hline & CSEG $(\mathrm{n}=20)$ & LSEG $(\mathrm{n}=20)$ & P \\
\hline Age $(\mathrm{yrs})$ & $40.50 \pm 7.31$ & $39.60 \pm 6.05$ & 0.23 \\
Height(cm) & $165.1 \pm 4.25$ & $168.7 \pm 6.52$ & 0.53 \\
Weight(kg) & $58.00 \pm 4.33$ & $60.12 \pm 4.33$ & 0.41 \\
\hline $\begin{array}{l}\text { M } \pm \text { SD }=\text { Mean } \pm \text { Standard Deviation } \\
\text { CSEG=Cervical stabilization exercise group }\end{array}$ \\
LSEG=Lumbar stabilization exercise group
\end{tabular}


Table 2. Program of cervical stabilization exercises

\begin{tabular}{|c|c|c|}
\hline Classification & Variety of Exercises & Time \\
\hline Warm-up & Joints and muscles stretching & $5 \mathrm{~min}$ \\
\hline $\begin{array}{c}\text { Cervical stabilization } \\
\text { exercise }\end{array}$ & $\begin{array}{l}\text { 1. stabilizer bag pressing exercise } 20 \mathrm{mmHg} \\
\text { 2. stabilizer bag pressing exercise } 22 \mathrm{mmHg} \\
\text { 3. stabilizer bag pressing exercise } 24 \mathrm{mmHg} \\
\text { 4. stabilizer bag pressing exercise } 26 \mathrm{mmHg} \\
\text { 5. stabilizer bag pressing exercise } 28 \mathrm{mmHg} \\
\text { 6. stabilizer bag pressing exercise } 30 \mathrm{mmHg}\end{array}$ & $\begin{array}{c}30 \mathrm{~min} \\
\text { (each } 1 \text { set } 10 \text { inning } 10 \mathrm{sec} \text {, } \\
\text { rest } 3 \sim 5 \mathrm{sec} \text { ) }\end{array}$ \\
\hline Warm-down & Joints and muscles stretching & $5 \mathrm{~min}$ \\
\hline
\end{tabular}

Table 3. Program of lumbar stabilization exercises

\begin{tabular}{|c|c|c|}
\hline Classification & Variety of Exercises & Time \\
\hline Warm-up & Joints and muscles stretching & $5 \mathrm{~min}$ \\
\hline \multirow{7}{*}{$\begin{array}{c}\text { Lumbar stabilization } \\
\text { exercise }\end{array}$} & $\begin{array}{l}\text { 1. Quadrupedal position } \\
\text { 2. Three-point kneeling } \\
\text { arm lift exercise }\end{array}$ & \\
\hline & 3. Three-point kneeling & $30 \mathrm{~min}$ \\
\hline & leg lift exercise & (each 1set 12 inning \\
\hline & 4. Two-point kneeling & $20 \sim 25 \mathrm{sec}$, rest $30 \mathrm{sec}$ ) \\
\hline & arm \& leg lift exercise & \\
\hline & 5. Crawling exercise & \\
\hline & 6. Bridge exercise & \\
\hline Warm-down & Joints and muscles stretching & $5 \mathrm{~min}$ \\
\hline
\end{tabular}

\section{Measurement of quantitative sensory testing} TSA-II NeuroSensory Analyzer ${ }^{\circledR}$ (Medoc, Ramat, Israel) was selected to evaluate nerve impairment and apply a QST. The subjects sat on a chair in a quiet room and a temperature detector was attached to C2 spinous process. The warm sensation threshold (WST) and cold sensation threshold (CST) was measured by either increasing or decreasing the temperature by 1 ${ }^{\circ} \mathrm{C}$ every second after setting a baseline temperature. The heat pain threshold (HPT) and cold pain threshold (CPT), i.e., the temperature at which the stimulus was experienced as painful by the subjects, was determined at the pushing of a button by the subjects. The thermal sensation threshold was measured four times using a 4- to 6-second resting time in between. The average was then used in the analysis. Similarly, the pain threshold was measured three times with a 10 -second resting time in between and the average of the three measures was utilized in the analysis. All the temperatures were determined using baseline, maximum, and minimum temperatures of $30^{\circ} \mathrm{C}, 50{ }^{\circ} \mathrm{C}$, and $0^{\circ} \mathrm{C}$, respectively. In cases where the subjects did not feel a warm sensation/heat-related pain or a cold sensation/cold-related pain, respectively, $50^{\circ} \mathrm{C}$ and $0^{\circ} \mathrm{C}$ were used as the thresholds. ${ }^{27)}$

\section{Data analysis}

SPSS $^{\circledR}$ (version18.0) was used for statistical analysis. The mean \pm standard deviation was obtained for each variable. Independen $\mathrm{t}$-test, aparametric method was employed to evaluate the homogeneity of the general characteristics of the subjects. Two-way repeated measures analysis of variance(ANOVA) was conducted to assess the between-group difference of the measured variables, depending on the measurement time used. Statistically significance was set at $a=0.05$. 


\section{Results}

\section{Changes in muscular activity}

Muscular activity in the sternocleidomastoid muscle increased by $10.17 \mu \mathrm{V}$ and $3.92 \mu \mathrm{V}$ in the cervical and lumbar stabilization exercise groups, respectively. Muscular activity in the anterior scalene muscle increased by $5.98 \mu \mathrm{V}$ in the cervical stabilization exercise group and decreased by $1.28 \mu \mathrm{V}$ in the lumbar stabilization exercise group. A statistically significant difference was observed regarding changes in the muscular activity of the sternocleidomastoid ( $p<0.05$ ) and anterior scalene $(\mathrm{p}<0.01)$ muscles between the groups depending on the measurement time used. The statistically significant difference of interaction by time and group shown in the two-way repeated measures ANOVA implies that the changes in the muscular activity according to time is different between the two groups (Table 4).

\section{Changes in quantitative sensory testing}

The CST increased by $2^{\circ} \mathrm{C}$ and $0^{\circ} \mathrm{C}$ in the cervical and lumbar stabilization exercise groups, respectively. A statistically significant difference between the two groups $(\mathrm{p}<0.01)$ was observed regarding changes in the CST, depending on the measurement time used. The statistically significant difference of interaction by time and group that was shown in the two-way repeated measures ANOVA implies that the change of
CST according to time is different between the two groups.

The WST decreased by $5^{\circ} \mathrm{C}$ and $3^{\circ} \mathrm{C}$ in the cervical and lumbar stabilization exercise groups, respectively. This difference between the two groups ( $\mathrm{p}<0.05$ ), based on the measurement time employed, was also found to be statistically significant. The statistically significant difference of interaction by time and group shown in the two-way repeated measures ANOVA implies that the change of WST according to time is different between the two groups.

The CPT increased by $8^{\circ} \mathrm{C}$ and $4{ }^{\circ} \mathrm{C}$ in the cervical and lumbar stabilization exercise groups, respectively. Once again, this difference between the groups ( $\mathrm{p}<$ 0.05), depending on the measurement time used, was found to be statistically significant. The statistically significant difference of interaction by time and group shown in the two-way repeated measures ANOVA implies that the change of CPT according to time is different between the two groups.

Lastly, the HPT decreased by $3^{\circ} \mathrm{C}$ and $2^{\circ} \mathrm{C}$ in the cervical and lumbar stabilization exercise groups, respectively. Yet again, based on the previously outlined parameters, this difference was observed to have statistical significance $(\mathrm{p}<0.05)$. The statistically significant difference of interaction by time and group shown in the two-way repeated measures ANOVA implies that the change of HPT according to time is different between the two groups. (Table 5).

Table 4. Changes in muscular activity (Unit : $\mu \mathrm{V}$ )

\begin{tabular}{|c|c|c|c|c|}
\hline & Group & Pre & Post & $F$ \\
\hline \multirow{3}{*}{ SCMM } & CSEG $(n=20)$ & $15.68 \pm 4.65$ & $25.85 \pm 9.33$ & $\mathrm{~T}: 8.290^{*}$ \\
\hline & & & & G: 1.887 \\
\hline & LSEG $(n=20)$ & $16.41 \pm 4.14$ & $20.33 \pm 6.41$ & $\mathrm{~T} \times \mathrm{G}: 5.206^{*}$ \\
\hline \multirow{3}{*}{ ASM } & CSEG $(n=20)$ & $25.64 \pm 4.24$ & $31.62 \pm 5.30$ & $\mathrm{~T}: 13.112^{* *}$ \\
\hline & & & & G: 2.128 \\
\hline & LSEG $(n=20)$ & $27.40 \pm 3.55$ & $26.12 \pm 3.67$ & $\mathrm{~T} \times \mathrm{G}: 14.491^{* *}$ \\
\hline
\end{tabular}

$\mathrm{M} \pm \mathrm{SD}, \mathrm{T}$ : time, $\mathrm{G}$ : group, ${ }^{*}: \mathrm{p}<.05,{ }^{* *}: \mathrm{p}<.01$

CSEG=Cervical stabilization exercise group

LSEG=Lumbar stabilization exercise group

SCMM=Sternocleidomastoid muscle

ASM=Anterior scalene muscle 
Table 5. Changes in quantitative sensory testing (Unit : ${ }^{\circ} \mathrm{C}$ )

\begin{tabular}{|c|c|c|c|c|}
\hline & Group & Pre & Post & $F$ \\
\hline \multirow{3}{*}{ CST } & $\operatorname{CSEG}(\mathrm{n}=20)$ & $25.56 \pm 1.67$ & $27.10 \pm 2.09$ & $\mathrm{~T}: 18.107^{* * *}$ \\
\hline & & & & G: 0.257 \\
\hline & LSEG $(n=20)$ & $26.64 \pm 2.94$ & $26.79 \pm 3.04$ & $\mathrm{~T} \times \mathrm{G}: 17.414^{* *}$ \\
\hline \multirow{3}{*}{ WST } & CSEG $(n=20)$ & $39.48 \pm 2.20$ & $34.38 \pm 1.54$ & $\mathrm{~T}: 24.338^{* * * *}$ \\
\hline & & & & G: 0.063 \\
\hline & LSEG（n=20） & $34.89 \pm 1.93$ & $31.42 \pm 1.94$ & $T \times G: 7.712^{* * *}$ \\
\hline \multirow{3}{*}{$\mathrm{CPT}$} & $\operatorname{CSEG}(n=20)$ & $20.10 \pm 6.17$ & $28.56 \pm 1.40$ & $\mathrm{~T}:$ 7.362* \\
\hline & & & & G: 0.565 \\
\hline & LSEG $(n=20)$ & $24.22 \pm 4.52$ & $27.75 \pm 1.98$ & $\mathrm{~T} \times \mathrm{G}: 13.129^{* * *}$ \\
\hline \multirow{3}{*}{ HPT } & $\operatorname{CSEG}(n=20)$ & $45.56 \pm 3.92$ & $42.41 \pm 3.88$ & $\mathrm{~T}: 22.460^{* * * *}$ \\
\hline & $J \mathrm{CLC} C(\mathrm{n}-20)$ & $150<+20^{2}$ & $1025+200$ & G: 0.337 \\
\hline & LSEG $(n=20)$ & $45.84 \pm 2.93$ & $44.25 \pm 2.88$ & $\mathrm{~T} \times \mathrm{G}: \quad 6.150^{*}$ \\
\hline
\end{tabular}

$\mathrm{M} \pm \mathrm{SD}, \mathrm{T}$ : time, G: group, ${ }^{*}: \mathrm{p}<.05,{ }^{* *}: \mathrm{p}<.01,{ }^{* * *}: \mathrm{p}<.001$

CSEG=Cervical stabilization exercise group

LSEG=Lumbar stabilization exercise group

CST=Cold sensation threshold

WST $=$ Warm sensation threshold

CPT=Cold pain threshold

HPT=Heat pain threshold

\section{Discussion}

Range of motion in the cervical spine is categorized as cervical spine mobility, head and neck mobility, and combined cervical spine mobility. Flexible movement in the cervical spine is supported by the superficial muscles, i.e., the sternocleidomastoid and anterior scalene muscles. ${ }^{28,29)}$ The cervical spine plays a key role in posture control by supporting the head and maintaining trunk stability. In particular, a health cervical lordosis is maintained by co-contraction of the muscles around the cervical spine. ${ }^{28)}$ Increasing attention is being given to the ability of the superficial muscles to maintain posture control and cervical spine stability. ${ }^{29)}$ Cervical and lumbar stability refers to the ability to maintain the spine in a neutral position through appropriate control of the muscles surrounding the cervical and thoracic vertebrae, and the lumbar and pelvis. ${ }^{30)}$ Disturbance to the neutrality of the position of the head and neck can cause pain due to hypertonicity of the surrounding muscles. It has been proposed that muscle hypertonicity and pain can be re- duced by improving the ability to maintain a neutral head-neck position through cervical stabilization exercises as these expedite the contraction of muscles around the cervical spine. ${ }^{31}$

Lumbar stabilization exercises are used to enhance the stability of lumbar spine and induce balanced posture control and trunk stability by improving contraction in the skeletal muscles around the spine (i.e., erector spinae, musculus transversus abdominis, multifidus, and lumbar quadrate) that contribute to lumbar spine and pelvic region stabilization. ${ }^{32)}$ In particular, lumbar stabilization exercises play an important role in achieving spine stability and postural control by increasing muscular activity in the abdomen, lumbar spine, and pelvic region. ${ }^{33)}$

\section{Changes in muscular activity}

Changes in muscular activity (i.e., the sternocleidomastoid and anterior scalene muscles) of patients with neck pain, before and after the cervical and lumbar stabilization exercises, were assessed in the current study. The study objective was to examine the effect 
of each exercise on the muscular activity of the cervical spine and on sensory nerve function (quantitatively). The findings were statistically significant regarding changes in muscular activity between the groups. The muscular activity of the sternocleidomastoid muscle increased by $10.17 \mu \mathrm{V}$ and 3.92 $\mu \mathrm{V}$ in the cervical and lumbar stabilization exercise groups, respectively. Muscular activity in the scalene muscle also increased by $5.98 \mu \mathrm{V}$ in the cervical stabilization exercise group, but decreased by $1.28 \mu \mathrm{V}$ in the lumbar stabilization exercise group, i.e., a significant change was observed following the intervention. This finding was consistent with that in the study by Jull et $\mathrm{al}^{3{ }^{34)}}$ in which the application of neck flexor strengthening exercises in patients with neck pain was also shown to result in an increase in sternocleidomastoid and anterior scalene muscular activity. Davies ${ }^{35)}$ reported that sternocleidomastoid and scalene muscle-related activity in the temporomandibular joint increased significantly during masticatory movement; consistent with the findings of our study.

\section{Changes in quantitative sensory testing}

The findings were also statistically significant regarding changes in quantitative sensory testing (determined quantitatively). The CST increased by $2{ }^{\circ} \mathrm{C}$ and $0^{\circ} \mathrm{C}$, the WST decreased by $5^{\circ} \mathrm{C}$ and $3^{\circ} \mathrm{C}$, the $\mathrm{CPT}$ increased by $8^{\circ} \mathrm{C}$ and $4^{\circ} \mathrm{C}$, and the HPT decreased by $3^{\circ} \mathrm{C}$ and $2^{\circ} \mathrm{C}$, in the cervical lumbar stabilization exercise groups, respectively. These findings were all statistically significant. These results were consistent with those of Johnston,36) who reported a significant change in the CST and WST in office workers following cervical stabilization exercises. Chien ${ }^{37)}$ applied cervical stabilization exercises to patients with neck pain due to whiplash injury. Significant changes in the CPT and HPT were reported; similar to our study finding. The results of the current study were also partially consistent with those reported by Celenay et $\mathrm{al}^{38)}$, i.e., of a significant change in cervical pain in patients with neck pain following cervical and scapulothoracic stabilization exercises with and without connective tissue massage.
The use of cervical and lumbar stabilization exercises in patients with neck pain over four weeks in the current study resulted in a significant increase in sternocleidomastoid and anterior scalene muscle-related activity, an increase in the CST and CPT, and a significant decrease in the WST and HPT, following the intervention. This indicates that cervical stabilization exercises and lumbar stabilization exercises improved the activity and contraction of the muscles involved in ensuring cervical spine stability, thus exerting a positive influence on the ability to experience thermal sensation, i.e., thereby enabling a quantitative assessment of neuropathic pain. Thus, the combined use of cervical and lumbar stabilization exercises is recommended as an exercise program for patients with neck pain seeking an improvement in cervical spine stability.

\section{Conclusion}

The effect of a combination of cervical and lumbar stabilization exercises over a four-week period on changes in muscular activity and QST in the cervical spine was evaluated in the current study. Thus, changes in the muscular activity of the sternocleidomastoid and anterior scalene muscles, as well as in the CST, WST, CPT, and HPT of patients with neck pain, was measured before and after the intervention. A statistically significant increase and decrease was observed regarding changes in the CST and CPT, and in the WST and HPT, respectively.

Thus, the use of cervical and lumbar stabilization exercises improved the activity and contraction of the muscles involved in cervical spine stability in the study participants, thereby positively influencing the ability to experience thermal sensation and enabling the quantitative assessment of neuropathic pain. In addition to cervical stabilization exercises, lumbar stabilization exercises should be considered as an exercise program for patients with neck pain, with the objective of improving cervical spine stability. 


\section{References}

1. Tepper M, Vollenbroek-Hutten MMR, Hermens HJ, et al. The effect of an ergonomic computer device on muscle activity of the upper trapezius muscle during typing. Appl Ergon. 2003;34(2):125-30.

2. Cassidy JD, Carroll L, Peloso P, et al. Incidence, risk factors and prevention of mild traumatic brain injury: results of the WHO Collaborating Centre Task Force on Mild Traumatic Brain Injury. J Rehabil Med. 2004;36(0):28-60.

3. Hudson JS, Ryan CG. Multimodal group rehabilitation compared to usual care for patients with chronic neck pain: a pilot study. Man Ther. 2010;15(6):552-6.

4. Cagnie B, Danneels L, Van Tiggelen D, et al. Individual and work related risk factors for neck pain among office workers: a cross sectional study. Eur Spine J. 2007;16(5):679-86.

5. Wright EF, Domenech MA, Fischer JR. Usefulness of posture training for patients with temporomandibular disorders. J Am Dent Assoc. 2000;131(2):202-10.

6. Kingma I, van Dieën JH. Static and dynamic postural loadings during computer work in females: Sitting on an office chair versus sitting on an exercise ball. Appl Ergon. 2009;40(2):199-205.

7. Ferrari S, Monticone M. Efficacy of a multimodal rehabilitation program in a dental hygienist with upper quadrant disorders. Description of a case report with one-year follow-up. G Ital Med Lav Erg. 2009;31(4): 407-13.

8. Bergqvist U, Wolgast E, Nilsson B, et al. Musculoskeletal disorders among visual display terminal workers: individual, ergonomic, and work organizational factors. Ergon. 1995;38(4):763-76.

9. Hagberg M. Occupational musculoskeletal stress and disorders of the neck and shoulder: a review of possible pathophysiology. Int Arch Occup Environ Health. 1984;53(3):269-78.

10. Luoto S, Aalto H, Taimela S, et al. One-Footed and Externally Disturbed Two-Footed Postural Control in Patients With Chronic Low Back Pain and Healthy Control Subjects: A Controlled Study With Follow-Up. Spine. 1998;23(19):2081-9.

11. Falla DL, Campbell CD, Fagan AE, et al. Relationship between cranio-cervical flexion range of motion and pressure change during the cranio-cervical flexion test.
Man Ther. 2003;8(2):92-6.

12. Falla D, Rainoldi A, Merletti R, et al. Myoelectric manifestations of sternocleidomastoid and anterior scalene muscle fatigue in chronic neck pain patients. Clin Neurophysiol. 2003;114(3):488-95.

13. Ylinen J, Takala EP, Nykänen $M$, et al. Active neck muscle training in the treatment of chronic neck pain in women: a randomized controlled trial. Jama, 2003;289(19):2509-16.

14. Baltaci G, Un N, Tunay V, et al. Comparison of three different sit and reach tests for measurement of hamstring flexibility in female university students. Br J Sports Med. 2003;37(1):59-61.

15. Edwards J. The importance of postural habits in perpetuating myofascial trigger point pain. Acupunct Med. 2005;23(2):77-82.

16. Scheer JK, Tang JA, Smith JS, et al. Cervical spine alignment, sagittal deformity, and clinical implications: a review. Journal of Neurosurgery: Spine. 2013;19(2), 141-59.

17. McGill SM. Low back stability: from formal description to issues for performance and rehabilitation. Exerc Sport Sci Rev. 2001;29(1):26-31.

18. Behm DG, Drinkwater EJ, Willardson JM, et al. The use of instability to train the core musculature. Appl Physiol Nutr Metab. 2010;35(1):91-108.

19. Falla D, O'Leary S, Fagan A, et al. Recruitment of the deep cervical flexor muscles during a postural-correction exercise performed in sitting. Man Ther. 2007;12(2): 139-43.

20. Standaert CJ, Weinstein SM, Rumpeltes J. Evidenceinformed management of chronic low back pain with lumbar stabilization exercises. Spine J. 2008;8(1):114-20.

21. Cabanas-Valdés R, Bagur-Calafat C, Girabent-Farrés M, et al. The effect of additional core stability exercises on improving dynamic sitting balance and trunk control for subacute stroke patients: a randomized controlled trial. Clin Rehabil. 2016;30(10):1024-33.

22. Dusunceli Y, Ozturk C, Atamaz F, et al. Efficacy of neck stabilization exercises for neck pain: a randomized controlled study. J Rehabil Med. 2009;41(8):626-31.

23. Wegner S, Jull G, O'Leary S, et al. The effect of a scapular postural correction strategy on trapezius activity in patients with neck pain. Man Ther. 2010;15(6):562-6.

24. Johnston V, Jimmieson NL, Jull G, et al. Quantitative 
sensory measures distinguish office workers with varying levels of neck pain and disability. PAIN®. 2008;137 (2):257-65.

25. Conley MS, Meyer RA, Feeback DL, et al. Noninvasive analysis of human neck muscle function. Spine. 1995;20(23):2505-12.

26. Boyd-Clark LC, Briggs CA, Galea MP. Muscle spindle distribution, morphology, and density in longus colli and multifidus muscles of the cervical spine. Spine. 2002;27(7):694-701.

27. Marshall PW, Murphy BA. Core stability exercises on and off a Swiss ball. Arch Phys Med Rehabil. 2005;86(2): 242-9.

28. Dusunceli Y, Ozturk C, Atamaz F, et al. Efficacy of neck stabilization exercises for neck pain: a randomized controlled study. J Rehabil Med. 2009;41(8):626-31.

29. Dean E, Ross J. Discordance between cardiopulmonary physiology and physical therapy: toward a rational basis for practice. Chest. 1992;101(6):1694-8.

30. Willson JD, Dougherty CP, Ireland ML, et al. Core stability and its relationship to lower extremity function and injury. J Am Acad Orthop Surg. 2005;13(5):316-25.

31. Jull G, Falla D, Vicenzino B, et al. The effect of therapeutic exercise on activation of the deep cervical flexor muscles in people with chronic neck pain. Man Ther. 2009;14(6): 696-701.

32. Davies PL. Electromyographic study of superficial neck muscles in mandibular function. J Dent Res. 1979;58(1): 537-8.

33. Ohnston V, Jimmieson NL, Jull G, et al. Quantitative sensory measures distinguish office workers with varying levels of neck pain and disability. PAIN®. 2008;137(2):257-65.

34. Chien A, Eliav E, Sterling M. Whiplash (grade II) and cervical radiculopathy share a similar sensory presentation: an investigation using quantitative sensory testing. Clin J pain. 2008;24(7):595-603.

35. Celenay ST, Kaya DO, Akbayrak T. Cervical and scapulothoracic stabilization exercises with and without connective tissue massage for chronic mechanical neck pain: A prospective, randomised controlled trial. Man Ther. 2016;21:144-50. 